Article

\title{
Linear-Quadratic Regulator for Control of Multi-Wall Carbon Nanotube/Polydimethylsiloxane Based Conical Dielectric Elastomer Actuators
}

\author{
Titus Mulembo ${ }^{1}{ }^{0}$, Waweru Njeri ${ }^{1}$, Gakuji Nagai ${ }^{1}$, Hirohisa Tamagawa ${ }^{1}$, Keishi Naito ${ }^{1}$, \\ Takahiro Nitta $^{2}$ (D) and Minoru Sasaki ${ }^{1, *}$ \\ 1 Department of Mechanical Engineering, Faculty of Engineering, Gifu University, 1-1 Yanagido, \\ Gifu 501-1193, Japan; mulembo@gifu-u.ac.jp (T.M.); waweru@ymail.com (W.N.); gakuji@gifu-u.ac.jp (G.N.); \\ tmgwhrhs@gifu-u.ac.jp (H.T.); k_naito@gifu-u.ac.jp (K.N.) \\ 2 Department of Electrical \& Electronic Engineering, Applied Physics Course, Gifu University, 1-1 Yanagido, \\ Gifu 501-1193, Japan; nittat@gifu-u.ac.jp \\ * Correspondence: sasaki@gifu-u.ac.jp; Tel.: +81-582932541
}

Received: 2 February 2020; Accepted: 12 March 2020; Published: 13 March 2020

\begin{abstract}
Conventional rigid actuators, such as DC servo motors, face challenges in utilizing them in artificial muscles and soft robotics. Dielectric elastomer actuators (DEAs) overcome all these limitations, as they exhibit complex and fast motions, quietness, lightness, and softness. Recently, there has been much focus on studies of the DEAs material's non-linearity, the non-linear electromechanical coupling, and viscoelastic behavior of VHB and silicone-based conical DEAs having compliant electrodes that are based on graphite powder and carbon grease. However, the mitigation of overshoot that arises from fast response conical DEAs made with solid electrodes has not received much research focus. In this paper, we fabricated a conical configuration of multi-walled carbon nanotube/polydimethylsiloxane (MWCNT/PDMS) based DEAs with a rise time of $10 \mathrm{~ms}$, and 50\% peak overshoot. We developed a full feedback state-based linear-quadratic regulator (LQR) having Luenberger observer to mitigate the DEAs overshoot in both the voltage ON and OFF instances. The cone DEA's model was identified and a stable and well-fitting transfer function with a fit of $94 \%$ was obtained. Optimal parameters $Q=70,000, R=0.1$, and $Q=7000, R=0.01$ resulted in the DEA response having a rise time value of $20 \mathrm{~ms}$ with zero overshoot, in both simulations and experiments. The LQR approach can be useful for the control of fast response DEAs and this would expand the potential use of the DEAs as artificial muscles in soft robotics.
\end{abstract}

Keywords: controller; conical actuator; carbon nanotubes

\section{Introduction}

The fabrication and control of high-performance dielectric elastomers actuators (DEAs) can improve the state-of-the-art of artificial muscles and soft robotics [1,2]. DEAs are essentially two compliant electrodes sandwiching an insulating dielectric elastomer. The electrostatic pressure generated upon the voltage activation of the DEA causes the dielectric membrane to squeeze in the thickness direction and extend in the areal direction [3]. In as much as the working principle of the DEA looks simple, their behaviors have been challenging to model because of the DEA's material nonlinearity, nonlinear electromechanical coupling, instabilities, and breakdown of the DEAs [4].

Recently, various materials have been used in the fabrication of DEAs: Acrylic VHB 4910/4905 and silicone sheets have been used to make the insulating dielectric elastomer membranes while the electrodes were made from graphite powder or carbon grease [5]. However, these electrode materials would shift or enter the dielectric membrane and then cause premature failure and inconsistent 
performance of the DEA. Conductive fillers, such as carbon black and carbon nanotubes, have been used to fabricate conductive solid electrodes for diaphragm DEAs [6]. Acrylic-based DEAs have merits of large strains $(>380 \%)$, but they suffer from a lagged response and long viscoelastic relaxation times ( $>160$ s) due to their inherently soft nature [7]. Polydimethylsiloxane (PDMS) based DEAs have very small displacement strains $(<1 \%)$ and short response times $(\sim 10 \mathrm{~ms})$, hence they would be the best choice for the fabrication of ultrasound devices and fast-acting positioners [8-10].

Many configurations of DEAs have been fabricated depending on the application: stacked, helical, rolled, conical, double conical, planar, and folded DEAs [3]. Basic stack DEAs that are based on single layer planar DEAs have been fabricated for the generation of both high forces and high displacements [11,12]. Recently, conical DEAs have gained research attention since their output motions can be harnessed to make many promising commercial devices, such as ultrasonic speakers, positioners, valves, and pumps for fluids [13]. Conical DEAs take advantage of the lateral elongation along the cone membrane to generate large displacements. Besides, by stacking up single layers of cone DEA, both the advantages of high force and large displacements have been reported [14]. A remarkable number of cone DEAs were fabricated while using VHB and silicone-based dielectric elastomers, while their electrodes were made using carbon grease and graphite powder, where large strains and torques were reported $[13,15-18]$. For applications where the electrode needs to be durable and be able to support fluidic forces, solid electrodes can be a promising alternative. However, solid electrodes have not been popular, since they can restrict the deformation of a DEA. Hence, modeling that are techniques used in hyper-elastic DEAs would not necessarily be applicable to the DEAs having solid electrodes.

Recently, conical DEAs have been assumed to behave simply like a cone [19]. However, this simple representation fails to capture all of the cone DEA's complex and nonlinear behavior; therefore, improved dynamic models have been proposed [20,21]. Although such improved models have brought a better understanding of the electromechanical performance of the DEA, various control problems persist. One control problem would be the regulation of overshoot in the output trajectory of the DEA during the voltage on/off instances. Secondly, during the voltage ON duration, the DEAs continue to deform, while during the voltage OFF phase, the DEAs take a long time to return to its original dimension [22-24]. Lastly, the tracking of desired trajectories has been of a lot of research interest in using techniques, such as Proportional Integral Derivative (PID) control $[25,26]$. The viscoelastic creep and hysteresis, present in all rubber materials, necessitated the design of complicated PID compensators to control the DEAs. PID controllers have been reported in solving all the three control problems where the proportional gains were tuned for tracking of the displacements while the integrator and derivative gains were used for adjusting the high-frequency zones of the trajectories. One major drawback for many of the reported control studies, a minimum driving voltage of $500 \mathrm{~V}$ was used, since there was no significant response noticed in driving those DEAs below this voltage [25,27]. Most of the research focus was on regulating the overshoots for the voltage $\mathrm{ON}$ instances and reducing the viscoelastic relaxation during the $\mathrm{ON}$ phase. Other successful techniques to overcome the viscoelastic phenomenon have involved designing the cone actuator with both spring and mass or fabricating a double cone push-pull actuator [28]. However, such complicated designs only add to the weight and cost of the actuator. The Linear Quadratic approach has been successfully demonstrated for control of the speed of synchronous motors [22,23]. Unlike PID control, where three parameters have to be independently adjusted [29,30], the Linear Quadratic approach offers simplicity and robustness, since only two parameters need to be tuned, that is, the weight matrices $Q$, which penalizes the bad performance of the actuator, and $\mathrm{R}$, which penalizes the actuator effort. However, they do not exogenously penalize the performance and inputs, rather they alter the states, which in turn alter the performances and inputs. Therefore, the Linear Quadratic techniques look promising for use in DEA control.

In this study, we propose fabricating and controlling a fast-response conical DEA while using MWCNT/PDMS composites for the electrode and PDMS for the dielectric elastomer. The casting of the PDMS into intricate shapes and sizes would enable the fabrication of very thin membranes for the conical DEAs. Obtaining thin dielectric elastomer membranes would enable the precise driving of 
the DEAs with voltages that range from $0 \mathrm{~V}$ to $1 \mathrm{KV}$. We seek to make a single layer cone DEA having thickness of about $100 \mu \mathrm{m}$, which can comfortably carry a small mass of $0.15 \mathrm{~g}$ without tearing or stretching much. MWCNTs were selected as conductive fillers, since they have a high aspect ratio and would need a low loading content to result in a well-conducting composite [31]. We use a simple and low-cost dispersion technique that we developed earlier, which provides an MWCNT/PDMS composite with good conductivity at low MWCNT loading and yet the composite still remains flexible [32]. A well fabricated MWCNT/PDMS electrode would be durable, attach well to the dielectric elastomer, and would not leak into the dielectric elastomer.

To this end, system identification of the DEA was performed, and the transfer function was determined. The controllers were designed and implemented in Matlab/Simulink. A Luenberger observer was used to estimate all the states of the system. For the validation of the simulation, real-time closed-loop experimentation using a dSPACE controller board was implemented. The results show that the output of the DEA had no overshoots during both the voltage ON/OFF instances by optimally tuning the $\mathrm{Q}$ and $\mathrm{R}$ weight matrices, and a rise time of $20 \mathrm{~ms}$ was attained for both the closed-loop simulation and closed-loop experiment. This is the first cone DEA made by casting of PDMS and MWCNT/PDMS electrodes. It is the first attempt of a DEA made while using a two-layer membrane of electrode and dielectric elastomer pair. Additionally, it is the only cone DEA reported so far to be controlled using linear-quadratic regulator (LQR) and having a rise time of $10 \mathrm{~ms}$. The rest of the paper is organized as follows: Section 2 explains all the methods used from the design and fabrication of the DEA to modeling and development of controller. Section 3 presents the simulation and experimental results for the control of the cone DEA using the LQR controller. Section 4 gives the conclusions. Table 1 gives the nomenclature for abbreviations used in this paper.

Table 1. Nomenclature.

\begin{tabular}{ll}
\hline Notation & Full Name \\
\hline PDMS & Polydimethylsiloxane \\
DEA & Dielectric elastomer actuator \\
LQR & Linear quadratic regulator \\
PID & Proportional Integral Derivative \\
DC & Direct current \\
VHB & Very high bond \\
MWCNT & Multi wall carbon nanotube \\
PET & Polyethylene \\
DAC or D/A & Digital to analog converter \\
ADC or A/D & Analog to digital converter \\
\hline
\end{tabular}

\section{Methods}

\subsection{Development of the Cone DEA}

For the materials, MWCNTs having $10 \mu \mathrm{m}$ length, $10 \mathrm{~nm}$ average diameter, and $99 \%$ purity were obtained from Carbon Nano-material Technology Co. Ltd, Korea. PDMS (Silpot 184 elastomer Kit) was purchased from Dow Corning Toray. The PDMS is a two-part kit consisting of pre-polymer PDMS and a curing agent. The overview for the development of the DEA is as follows: First, the design of the single-layer cone DEA is explained. Secondly, the fabrication of the composite for the electrode is provided. The electrode is made from the MWCNT/PDMS composite. Thirdly, the casting of the two-layer membranes comprising an electrode membrane and a dielectric elastomer membrane is discussed. The dielectric elastomer is made from PDMS. Next, the fabricated membranes are assembled together to make a cone DEA and the cross-section of the DEA is examined by optical microscopy. Supporting frames and electrical contacts are affixed to the cone DEA. Finally, the DEA is setup ready for testing and the experimental phenomenon is described. 


\subsubsection{Design of the Cone DEA}

In the design of the cone DEA (Figure 1a), the rigid block at the center of the cone DEA is a mass to guide the stroke of the DEA vertically. The electrode was made from MWCNT/PDMS composites, while the dielectric elastomer was made from PDMS. The center dotted line running through the PDMS dielectric membrane shows where two PDMS membranes are in contact.

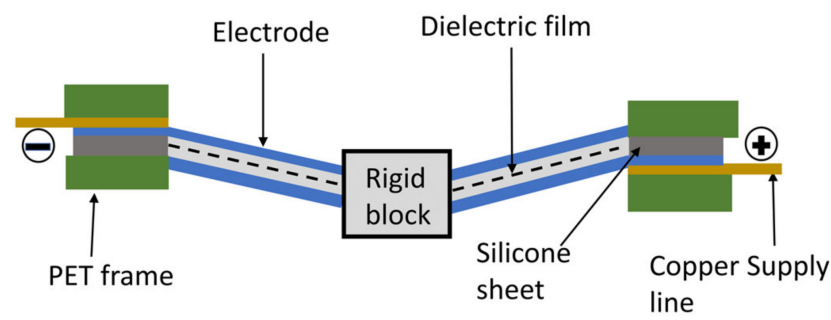

(a)

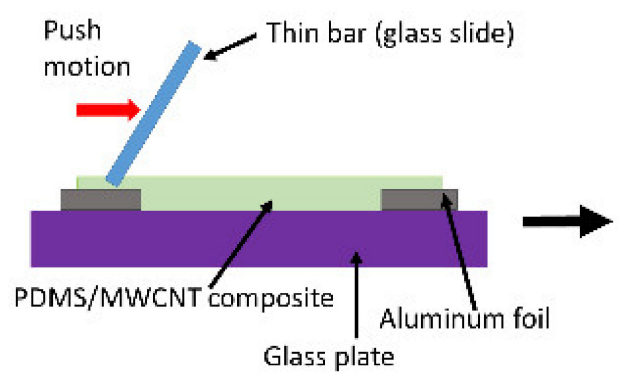

(b)

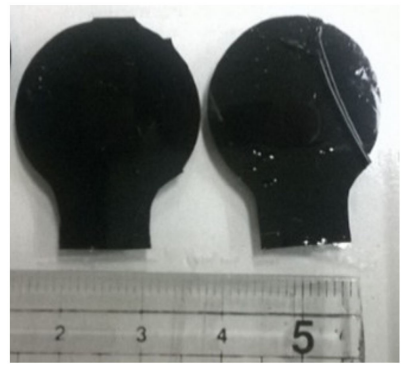

(c)
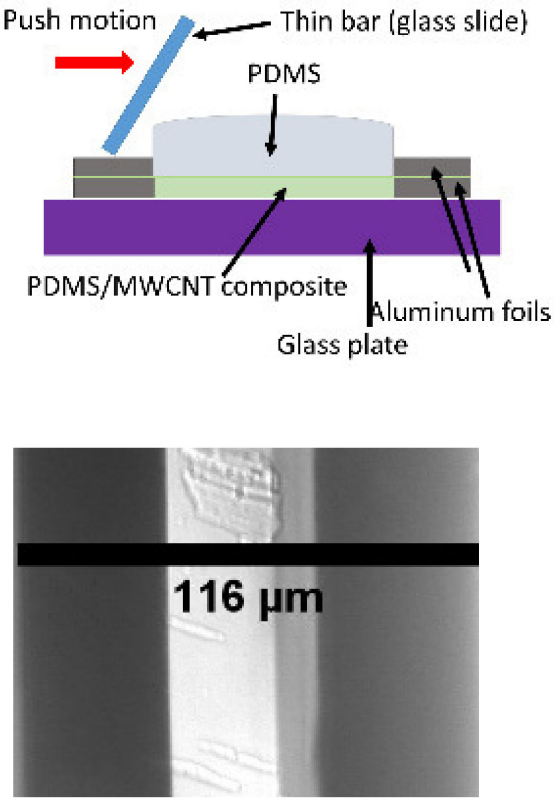

(d)

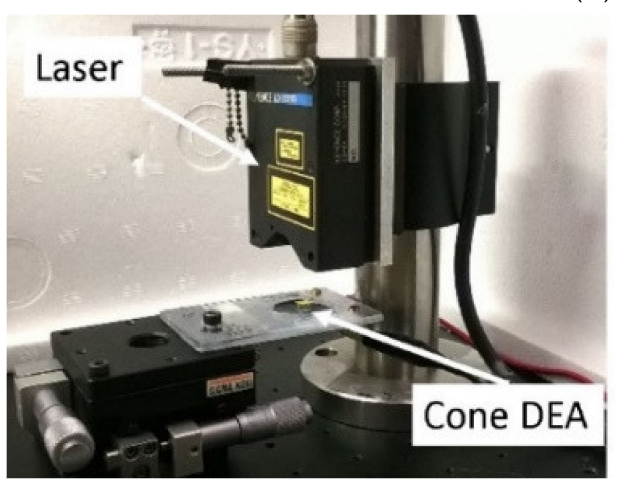

(e)

Figure 1. (a) Design of the cone DEA; (b) Fabrication of double-layer membranes consisting of a PDMS layer and a MWCNT/PDMS electrode layer by casting technique; (c) The membranes cut in circular shape with a protrusion for the attachment to power source; (d) Optical image of the cross-section of the cone DEA when the membranes of (c) are adjoined; (e) Positioning of the DEA below a laser for the measurement of the DEA vertical stroke. 


\subsubsection{Fabrication of Composite for the Electrode}

The fabrication of the composites for the electrodes of the DEA followed our reported procedure [32], where extensive preparation techniques and the characterization of the mechanical and electrical properties of the composites are presented. For the composite preparation, the MWCNTs were weighed on a weighing scale and then mixed with dispersing agents (naphthalene and toluene) at a mass ratio of 1:15:150 of MWCNT: naphthalene: toluene, in a glass bottle, and sonicated for $12 \mathrm{~h}$ in a sonication bath. Carbon nanotubes are always agglomerated, and effective dispersion is a must for obtaining improved conductivity. Later, the pre-polymer PDMS was added and the mixture was sonicated for another $12 \mathrm{~h}$. After sonication, the mixture was heated on a wide glass plate for $24 \mathrm{~h}$ at $100{ }^{\circ} \mathrm{C}$ to sufficiently remove the solvents. Before casting the composite to make the DEA electrode, the curing agent was added, and the mixture was crushed between two flat glass plates for $10 \mathrm{~min}$. to reduce any large aggregates of MWCNTs. Overall, the mass concentration of the MWCNT used in the MWCNT/PDMS composite was $2 \%$ after the curing agent was added to the mixture of MWCNT/pre-polymer PDMS.

\subsubsection{Mold Casting of the Electrode and Dielectric Elastomer Membranes}

Figure $1 \mathrm{~b}$ shows the casting of a two-layer membrane that consists of an MWCNT/PDMS electrode and the PDMS dielectric elastomer. We proposed fabricating a two-layer membrane for the easy handling or peeling of thin and soft membranes. Two aluminum foil strips of $40 \mathrm{~mm}$ width, $150 \mathrm{~mm}$ length, and thickness of $\sim 15 \mu \mathrm{m}$, are laid onto a clean flat glass plate and secured with tape to create a mold to fabricate the first layer (left of Figure $1 \mathrm{~b}$ ). The separation between the aluminum strips is $30 \mathrm{~mm}$. Crushed MWCNT/PDMS composite is poured on the mold and a flat glass blade is used to spread the composite to fill the mold. Heat curing was performed at $150{ }^{\circ} \mathrm{C}$ for $1 \mathrm{~h}$ and then cooled to solidify the composite. The second layer of aluminum foil guides is layered on the top of the previous ones to create a second mold, and a thin layer of PDMS is poured into the mold, being leveled by glass blade (right of Figure $1 \mathrm{~b}$ ) and heat cured at $150{ }^{\circ} \mathrm{C}$ for $1 \mathrm{~h}$. A 20:1 mass ratio of the pre-polymer PDMS to the curing agent was used for the fabrication of both the electrode and the dielectric elastomer membranes.

\subsubsection{Assembly of the Cone DEA}

Two circular electrode membranes having an allowance for the attachment of an external copper electrode (Figure 1c) are cut from the cast membranes by a knife using a circular guide of $24 \mathrm{~mm}$ diameter for the assembly of the DEA. The first membrane is positioned flat with the PDMS side facing up to layer a membrane pair on top of another membrane pair. Next, the top membrane is concentrically placed on top of the first layer with the PDMS face touching the PDMS face of the first membrane. Ethanol was used to concentrically facilitate the easy location of the membranes. This method of bringing PDMS faces together allowed for us to fabricate leakage-free DEA, even for such thin dielectric elastomer thickness. Leakage free DEAs would allow obtaining a fast response in DEAs. The assembled membranes were positioned and glued on to a silicone sheet having a circular hole that matches the diameter of the DEA membranes of Figure 1c. A circular hole with a diameter of $5 \mathrm{~mm}$ was cut out at the center of the DEA while using a round knife.

Optical microscopy was used to observe the cross-section of the DEA in the thickness direction. The test samples for the optical microscopy were obtained from the centerpiece that was cut out of the DEA membranes during the assembly process. A blade cut the test piece. For this DEA, the sample showed that the DEA thickness is about $116 \mu \mathrm{m}$ and the MWCNT/PDMS electrodes appear black in color and the whitish-grey part is the PDMS, as shown in the optical image of the cross-section of the DEA (Figure 1d).

A rigid circular disk cut out of a $5 \mathrm{~mm}$ thick PDMS sheet is glued at the hole in the center of the DEA while using PDMS as glue. This rigid block has a mass of 0.15 gand it acts as a load for the 
DEA. It also guides the deformation of the DEA downwards. Finally, the DEA was concentrically sandwiched between two rigid PET frames (in green in Figure 1a) having circular holes of $28 \mathrm{~mm}$ diameter each. Copper sheets were attached to the protruding end of the cone DEA electrodes that would supply power to the electrodes.

\subsubsection{Mounting the Cone DEA for Testing and Experimental Phenomenon}

The fabricated DEA was horizontally mounted on a workbench, where the center of the DEA is located below the laser head (Figure 1e). Care has to be taken in the test environment since the thin DEA is susceptible to vibrations and wind. A cover was used to deter wind, a vibration isolator was used to ward off ground vibrations, and the room ambient temperature was set at $25^{\circ} \mathrm{C}$. The DEA was allowed to acclimatize to the ambient conditions for one day before testing began. In between the tests, the DEA was allowed to rest for at least $10 \mathrm{~min}$.

\subsection{Modeling of the Cone DEA}

Input-output data were obtained, and they were used for the system identification of the cone DEA with aid of the MATLAB system identification toolbox to model the cone DEA. The Lennart Ljung identification method was used. The input-output data was sampled at $1 \mathrm{kHz}$ for $20 \mathrm{~s}$ overall. Here, a square waveform of $0 \mathrm{~V}$ to $1000 \mathrm{~V}$ and with a voltage $\mathrm{ON}$ and voltage OFF duration of $2 \mathrm{~s}$ each, was applied to the cone DEA in open-loop experimentation. We chose this voltage range, since, if $1000 \mathrm{~V}$ was exceeded, the DEA would get destroyed. We chose a switching duration of $2 \mathrm{~s}$ to observe the fast response of the DEA without letting the DEA undergo extensive viscoelastic relaxation. Even though the identified model would model all the regions of the DEA curve, the intention of our LQR controller was neither to flatten the long-time viscoelastic relaxation nor to compensate for the hysteresis. The main objective is to remove the overshoot when the voltage is turned ON or OFF and obtain a rise time in the tens of milliseconds range. For the model identification, one half of the data was used for estimation of the model and the other half was used for validation. Different numbers of poles and zeros were used to determine the best fit by trial and error method, as shown in Table 2.

Table 2. Fitting by trial and error.

\begin{tabular}{cccc}
\hline Poles & Zeros & Estimation Fit $\%$ & Validation Fit $\%$ \\
\hline 1 & 0 & 79.16 & 74.20 \\
2 & 0 & 89.29 & 87.54 \\
2 & 1 & 82.65 & 76.76 \\
3 & 1 & 91.59 & 88.99 \\
3 & 2 & 91.96 & 89.32 \\
4 & 0 & -0.37 & 3.97 \\
4 & 1 & 92.37 & 89.77 \\
4 & 2 & 93.42 & 91.40 \\
4 & 3 & 93.70 & 91.86 \\
5 & 0 & 17.40 & 15.97 \\
5 & 1 & 66.39 & 66.34 \\
5 & 2 & 93.82 & 92.48 \\
5 & 3 & 94.05 & 93.49 \\
5 & 4 & 94.08 & 93.70 \\
6 & 0 & -2.96 & -1.46 \\
6 & 1 & -76.23 & -69.55 \\
6 & 2 & 28.14 & 28.63 \\
6 & 3 & 94.09 & 93.92 \\
6 & 4 & 93.89 & 93.18 \\
6 & 5 & 94.06 & 93.96 \\
\hline
\end{tabular}

The models where the estimation fit and the validation fit were both above $93 \%$ were considered for stability analysis. This included models with poles/zero ratios of $5 / 3,5 / 4,6 / 3,6 / 4$, and $6 / 5$. Only one 
model, having five poles and three zeros, which was found to be stable and it was settled upon, and its transfer function is (1):

$$
\frac{958.1 \mathrm{~s}^{3}+2.607 \mathrm{e} 05 \mathrm{~s}^{2}+1.324 \mathrm{e} 06 \mathrm{~s}+3.459 \mathrm{e} 05}{\mathrm{~s}^{5}+177.7 \mathrm{~s}^{4}+7.074 \mathrm{e} 04 \mathrm{~s}^{3}+8.977 \mathrm{e} 06 \mathrm{~s}^{2}+3.728 \mathrm{e} 07 \mathrm{~s}+8.18 \mathrm{e} 06}
$$

The poles and zeros are:

Poles: $100 \times(-0.1968+2.5363 \mathrm{i},-0.1968-2.5363 \mathrm{i},-1.3406+0.0000 \mathrm{i},-0.0406+0.0000 \mathrm{i},-0.0023+0.0000 \mathrm{i})$ Zeros: $-266.8760,-4.8979,-0.2762$

\section{3. $L Q R$ Controller Design}

This subsection describes how the closed-loop LQR controller for the closed-loop experiment having a Luenberger observer was designed. Initially, the basic LQR controller configuration is derived from the state-space equations that were obtained from the DEA's plant transfer function. Next, a Luenberger observer for estimating the full states of the DEA is derived from the basic LQR controller. Subsequently, the basic LQR controller is augmented with the Luenberger observer, which is used for running the closed-loop simulation. Finally, the latter LQR controller was integrated into the closed-loop experimental setup.

\subsubsection{Basic LQR Controller}

Figure 2a shows the basic LQR controller configuration, which is a full state feedback controller. The command signal for the DEA is voltage, while the output is the vertical displacement of the cone DEA. The transfer function of the plant is first converted to the state-space model in Matlab. In a plant system, the state-space equations are given as (2):

$$
\begin{aligned}
& \dot{x}=A x+B u \\
& y=C x+D u
\end{aligned}
$$

where $\mathrm{u}$ is the input to the plant, $\mathrm{x}$ is the plant's state, $\mathrm{y}$ is the plant's output, $\mathrm{A}$ is the state matrix, $\mathrm{B}$ is the input matrix, $C$ is the output states, and $\mathrm{D}$ is the transfer matrix. For $\mathrm{LQR}$, the state-feedback law $\mathrm{u}$ $=-\mathrm{K} x$ minimizes the quadratic cost function $\mathrm{J}$ in a continuous-time (3):

$$
J=\int_{0}^{\infty}\left(x^{T} Q x+u^{T} R u\right) d t
$$

Subject to the Ricatti equation:

$$
A^{T} P+P A-(P B+N) R^{-1}\left(B^{T} P+N^{T}\right)+Q=0
$$

where $Q$ and $R$ are the weights and the controller gain $K$ is given by:

$$
K=R^{-1}\left(B^{T} P+N^{T}\right)
$$

We set the $\mathrm{Q}$ matrix to be a unit matrix of 5 by 5 , with its coefficient given as $\gamma$. The $\mathrm{K}$ gain is generated while using the LQR function in Matlab:

$$
\mathrm{K}=\mathrm{LQR}(\mathrm{A}, \mathrm{B}, \mathrm{Q}, \mathrm{R}) \text {, and let } \mathrm{Q}=\left[\begin{array}{ccccc}
\gamma & 0 & 0 & 0 & 0 \\
0 & \gamma & 0 & 0 & 0 \\
0 & 0 & \gamma & 0 & 0 \\
0 & 0 & 0 & \gamma & 0 \\
0 & 0 & 0 & 0 & \gamma
\end{array}\right]=\gamma\left[\begin{array}{lllll}
1 & 0 & 0 & 0 & 0 \\
0 & 1 & 0 & 0 & 0 \\
0 & 0 & 1 & 0 & 0 \\
0 & 0 & 0 & 1 & 0 \\
0 & 0 & 0 & 0 & 1
\end{array}\right]
$$




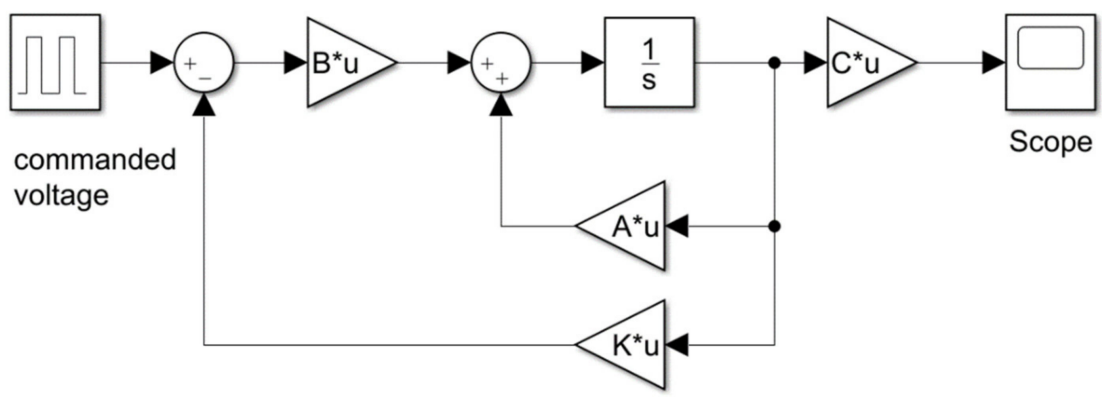

(a)

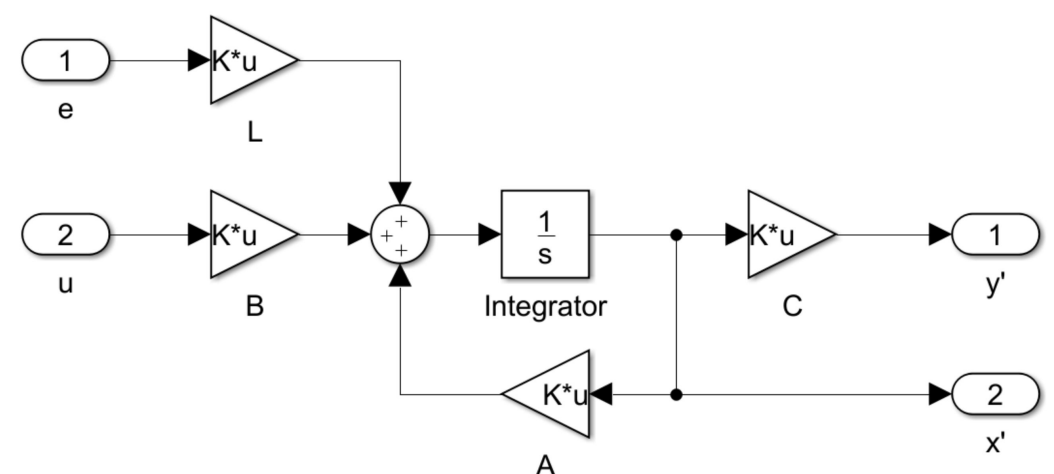

(b)

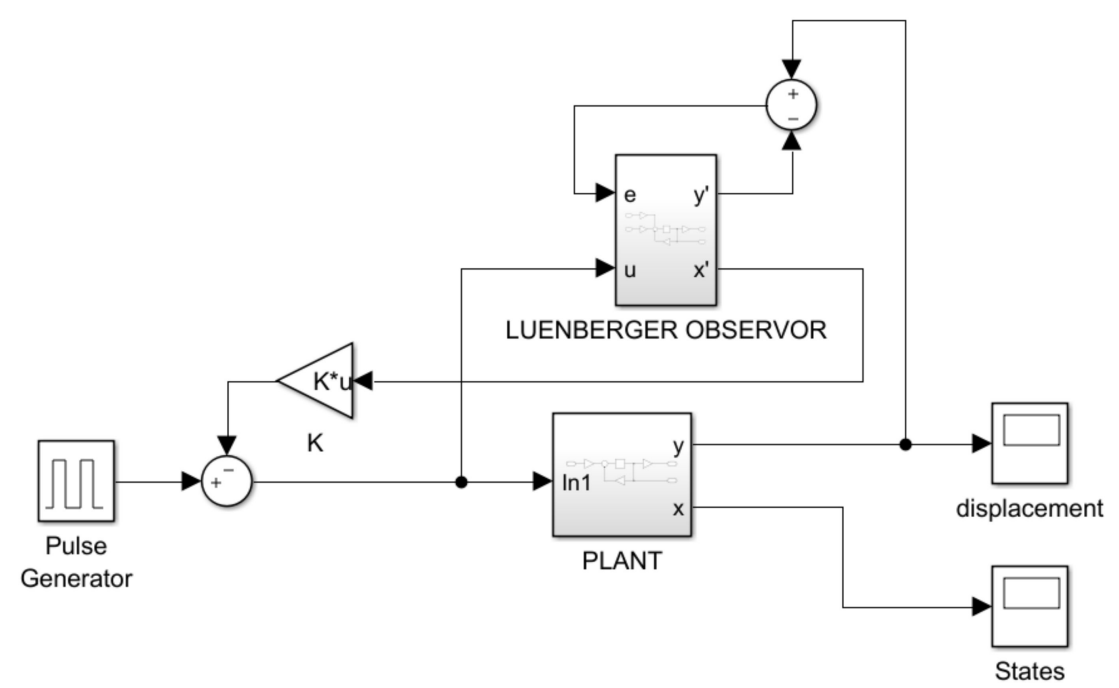

(c)

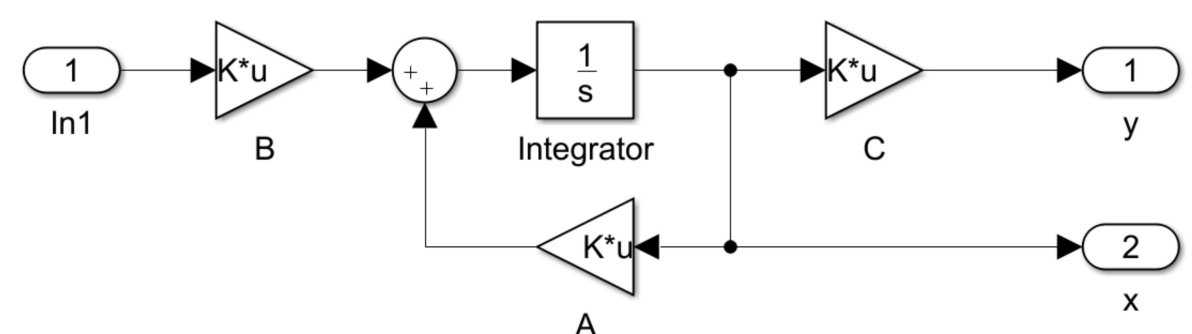

(d)

Figure 2. Cont. 


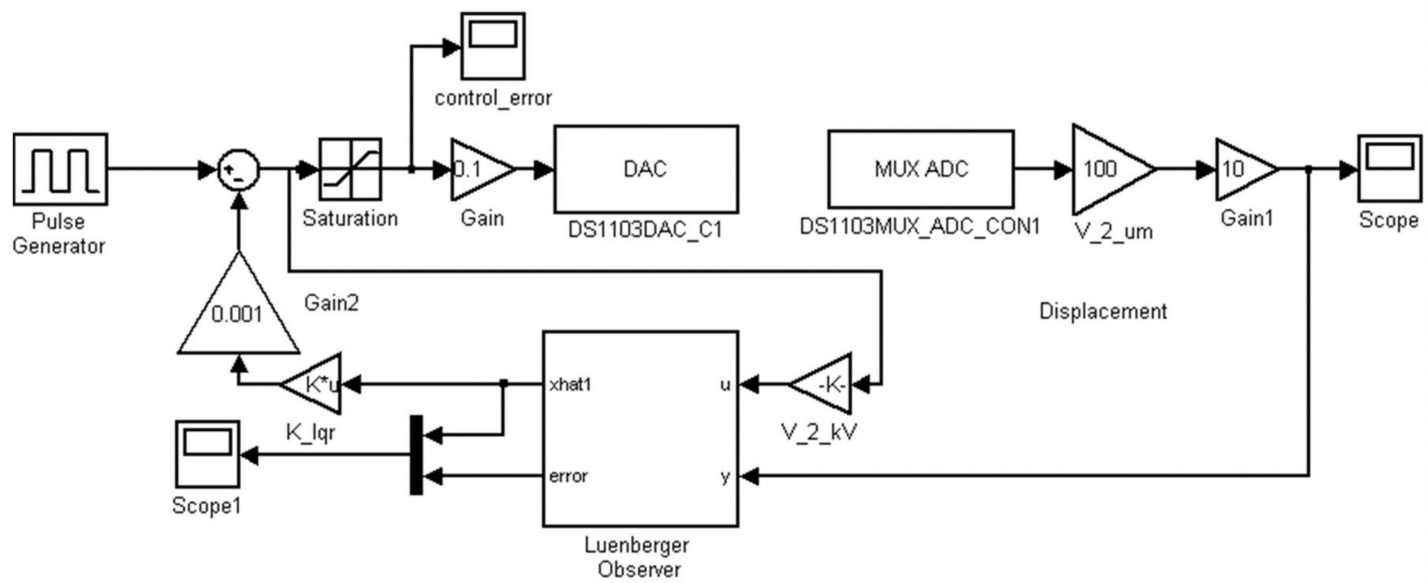

(e)

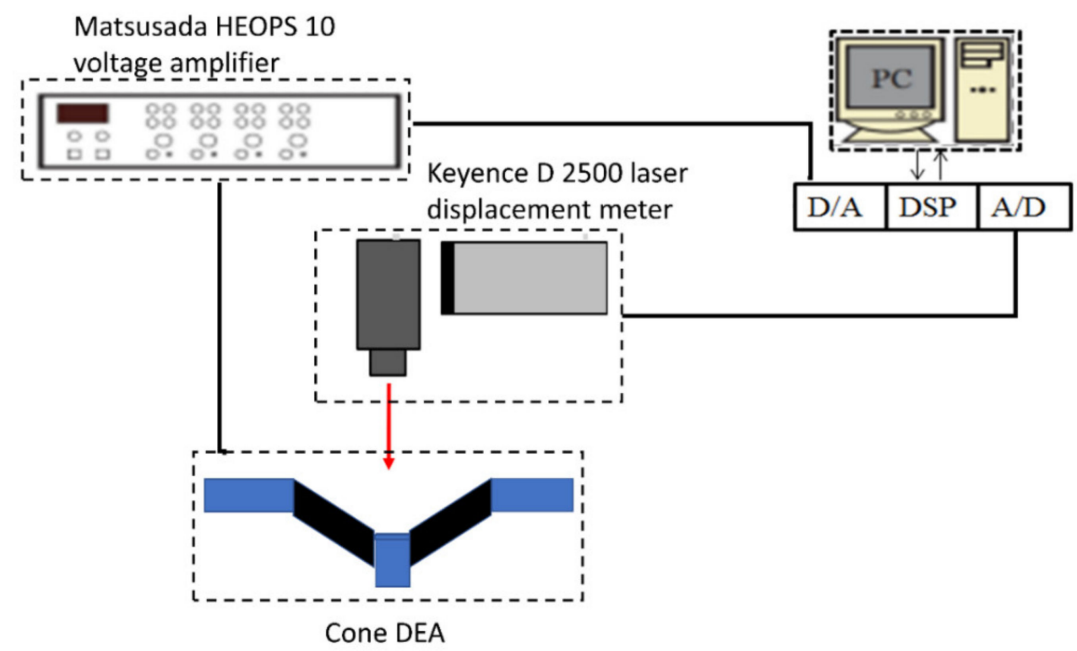

(f)

Figure 2. (a) The basic linear quadratic regulator controller; (b) A Luenberger observer; (c) An LQR controller having a Luenberger observer; (d) a plant model detail for the cone DEA; (e) LQR controller for real-time closed-loop experiment; and, (f) Block diagram for the experimental setup for the control of the cone DEA.

\subsubsection{Luenberger Observer Design}

A Luenberger state observer, as shown in Figure 2b, can be implemented with an LQR controller to approximate the states of the system in a real-time closed-loop experimental case where a system has many states that are unobservable or unmeasurable. The state observer uses state representation and its equations are given as (4):

$$
\begin{gathered}
\dot{x}^{\prime}=\mathrm{Ax}+\mathrm{Bu}+\mathrm{L}\left(\mathrm{y}-\mathrm{y}^{\prime}\right) \\
\dot{\mathrm{y}}=\mathrm{Cx}^{\prime}
\end{gathered}
$$

where $x^{\prime}$ is the estimated state, $y^{\prime}$ is the plant's estimated output, the error e is the difference between the estimated output, and the measured output. The gain $\mathrm{L}$ was obtained by pole placement method using the transform of $\mathrm{A}$ and $\mathrm{C}$ and the eigenmatrix of $\mathrm{A}$ using the Matlab place function:

$$
\mathrm{L}=\operatorname{PLACE}\left(\mathrm{A}^{\prime}, \mathrm{C}^{\prime}, \operatorname{eig}(\mathrm{A})\right)
$$




\subsubsection{LQR Controller Augmented with the Luenberger Observer}

An LQR controller having the Luenberger observer of Figure $2 b$ was designed and used for the closed-loop simulation and it is shown in Figure 2c. The estimated state $x^{\prime}$ generated by the Luenberger observer was fed back through the LQR controller gain $\mathrm{K}$ to be compared with the commanded voltage. The close-up of the plant model of Figure $2 b$ is used together with LQR observer and is shown in Figure 2d.

\subsubsection{Experimental Implementation of the LQR Controller with Luenberger Observer}

Figure 2e shows the experimental implementation of the LQR controller where saturation was implemented at $1100 \mathrm{~V}$ to prevent a breakdown of the DEA. Figure $2 \mathrm{f}$ shows the block diagram for the experiment setup for the real-time control of the cone DEA. In this operation, a Matsusada HEOPS $10 \mathrm{kV}$ voltage amplifier powers the cone DEA. A dSPACE controller board DS1103 was used to implement the communication to and from the computer to the DEA. The dSPACE controller board allows for a high rate of data sending and sampling of up to $100 \mathrm{kHz}$. However, we used $1 \mathrm{kHz}$ for this experiment. The voltage amplifier is controlled from the digital to analog converter (DAC) channel of the dSPACE controller board. A Keyence LD 2500 laser displacement meter measured the center stroke of the cone DEA vertically. The voltage signals from the laser displacement meter are input into the analog to digital converter (ADC) channel of the dSPACE controller board. Initially, open-loop experiments were performed, and a model of the cone DEA was identified from that data. Subsequently, open-loop experiments were conducted alongside closed-loop experiments for a comparison of data. This was also useful in order to factor in uncertainties that were brought by minute changes in ambient temperature and unforeseen material changes.

\section{Results and Discussion}

\subsection{Model Validation, Overshoot Criteria, and Viscoelastic Phenomenon}

The identified model was compared with its experimental data, as shown in Figure 3a,b, where the matching was very close. Figure 3 a shows the comparison for the first voltage ON and OFF cycle, where overshoot is apparent at both the voltage ON and voltage OFF instances. A close-up of the first $100 \mathrm{~ms}$ reveals that the DEA shows a peak overshoot at $12 \mathrm{~ms}$, as shown in Figure 3b. By comparing the first peak amplitude with the final value assumed at $100 \mathrm{~ms}$, the peak overshoot was $50 \%$ and the rise time was $10 \mathrm{~ms}$. The viscoelastic relaxation phenomenon was observed on this DEA under an applied constant voltage of $1000 \mathrm{~V}$, for $70 \mathrm{~s}$ (Figure 3c). Further, on voltage OFF, the DEA had an overshoot followed by a long period of about $70 \mathrm{~s}$ for the DEA to return to its initial condition. This is a creep phenomenon and is an inherent material property of rubber [33]. The removal of creep has not been our objective; we aim to eliminate the overshoot to zero percent, keeping the rise time to less than $30 \mathrm{~ms}$, while assuming a final value to be at $100 \mathrm{~ms}$.

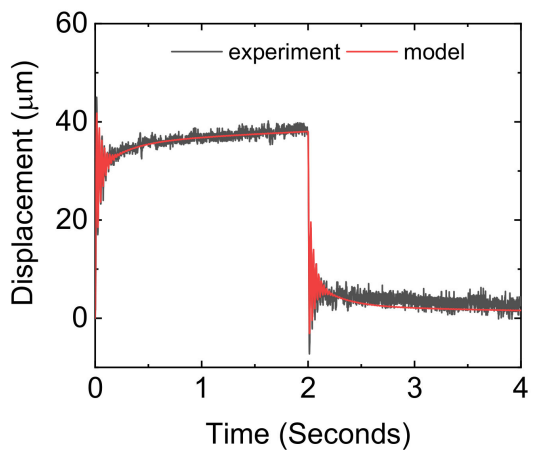

(a)

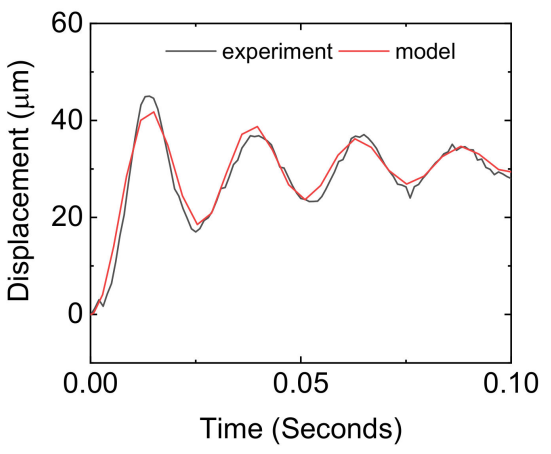

(b)

Figure 3. Cont. 


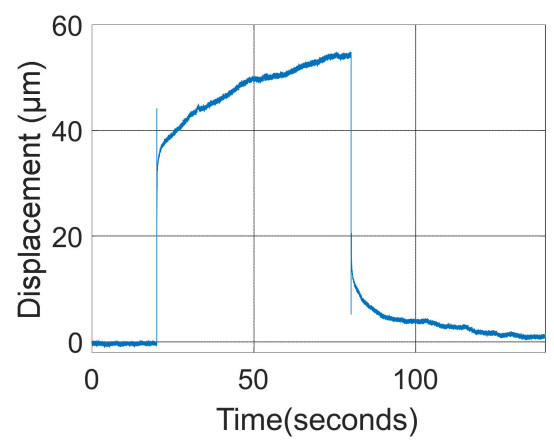

(c)

Figure 3. (a) Comparison of the open-loop experiment data with the identified model; (b) Close-up view of (a) for the first $100 \mathrm{~ms}$; and, (c) Creep phenomenon when DEA is actuated for long time spans, $70 \mathrm{~s}$ ON and $70 \mathrm{~s}$ OFF.

\subsection{Simulation Results}

The closed-loop performance of the LQR controller having a Luenberger observer (Figure 2c) was simulated with various values of $Q$ and $R$. First, different values of $Q$ are tested while holding $R$. Next, a median value of $Q$ is selected, and the values of $R$ were varied and tested. For uniformity, the parameters were incremented while using multiplication by 10 . For ease of reference, here we refer to the coefficient of $Q$ matrix just as $Q$, unless otherwise stated, since writing the full matrix of $Q$ would take a lot of space. These simulation results guided the selection of parameters for closed-loop experimentation. For the closed-loop simulation, the commanded voltage input was a square voltage the same as the one used for obtaining the input-output data.

\subsubsection{Effect of Varying Q}

Q was varied between 7 and 700,000 while $R$ was kept constant at 0.01 to investigate the effect of varying $Q$ on the response of the DEA (Figure 4). In Figure $4 a$, a large value of $Q=700,000$ resulted in the largest stroke of up to $300 \mu \mathrm{m}$, while the $\mathrm{Q}$ value of 7 resulted in about $35 \mu \mathrm{m}$ of displacement. Therefore, a larger value of $Q$ while holding $R$ resulted in a larger displacement. Figure $4 \mathrm{~b}$ shows a close-up of Figure $4 \mathrm{a}$ for the responses for the first $100 \mathrm{~ms}$, while assuming the final values to be at $100 \mathrm{~ms}$. $\mathrm{Q}=7$, recorded the lowest displacement, the fastest rise time $(<10 \mathrm{~ms})$, largest overshoot and aggressive response similar to the open-loop behavior in Figure 3b, while the $Q=700,000$ had a damped response (rise time $=75 \mathrm{~ms}$ ) and no overshoot (Figure $4 \mathrm{~b}$ ).

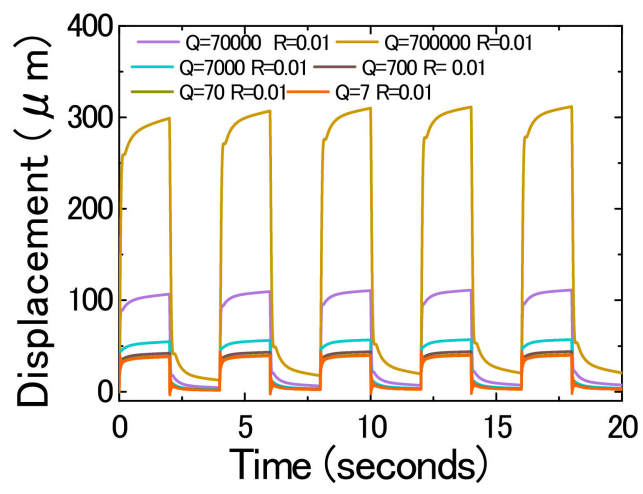

(a)

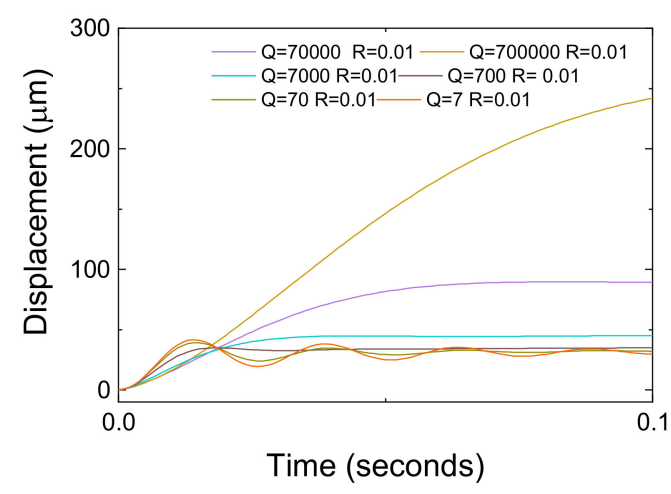

(b)

Figure 4. LQR simulation results comparison: (a) Varying Q; (b) close-up view of (a) for the first $100 \mathrm{ms.}$ 


\subsubsection{Effect of Varying $R$}

In Figure 5 a the value of $R$ was varied between 0.001 and 1 while holding $Q$ at 70,000 . A large value of $R$ of 1 resulted in the smallest response of $\sim 35 \mu \mathrm{m}$, while a very small $\mathrm{R}=0.001$ resulted in $\sim 300 \mu \mathrm{m}$ of displacement. Therefore, a smaller value of $\mathrm{R}$ while holding $\mathrm{Q}$ resulted in a larger displacement. Figure $5 \mathrm{~b}$ shows the response for the initial $100 \mathrm{~ms}$, as $\mathrm{R}$ got smaller the speed response became more damped. A large value of $R$ of 1 had an aggressive response with a peak overshoot at $12 \mathrm{~ms}$. A large value of $R$ has little effect on the mitigation of overshoot. In selecting the optimal parameters, we set the upper limit of the DEA displacement response to not exceed $70 \mu \mathrm{m}$ (Figure $5 \mathrm{~d}$ ). The values $\mathrm{R}=1$ and $\mathrm{R}=0.1$ for $\mathrm{Q}=70,000$ were considered for further optimization, and their responses are as shown in Figure $5 \mathrm{c}$ for the first voltage $\mathrm{ON}$ and OFF cycle. However, $\mathrm{R}=1$ had overshoot in its response at $12 \mathrm{~ms}$, this $\mathrm{R}$ value of $\mathrm{R}$ was disqualified. Hence, $\mathrm{Q}=70,000$ and $\mathrm{R}=0.1$ was considered to be best, with a rise time of $20 \mathrm{~ms}$.

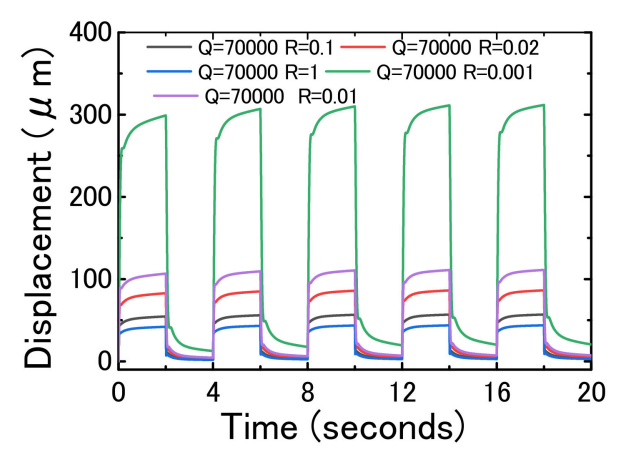

(a)

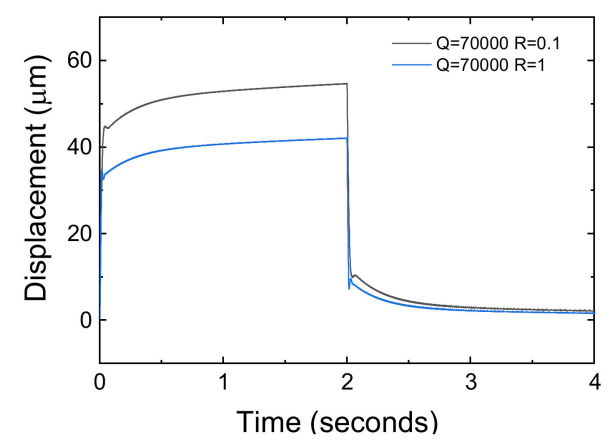

(c)

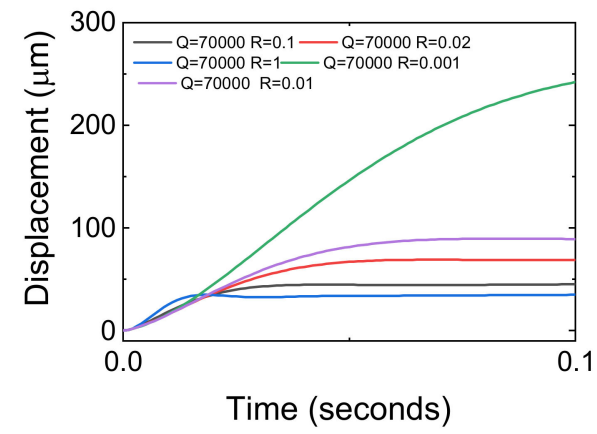

(b)

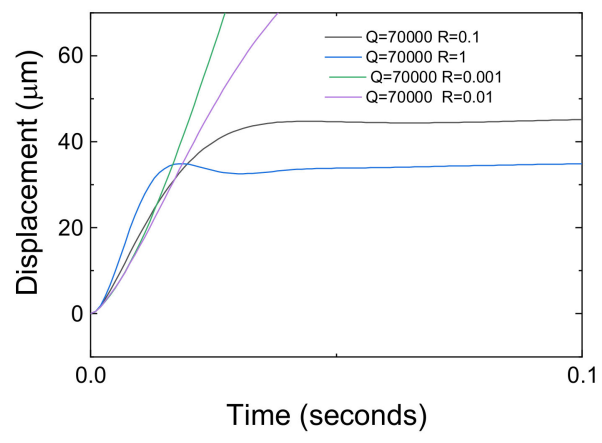

(d)

Figure 5. LQR simulation results comparison: (a) varying R; (b) Close-up view of (a) for the first $100 \mathrm{~ms}$; (c) For one voltage cycle; and, (d) Close-up view of (a) for the first $100 \mathrm{~ms}$ and upper cut-off of $70 \mu \mathrm{m}$.

\subsection{Experimental Results}

The LQR controller that was used in the simulation was implemented for the closed-loop experiment, as shown in Figure 2d. The effect of $Q$ and $R$ on the DEA performance was experimentally investigated. First, $Q$ was varied and run, followed by R. An open-loop experiment was performed together with the closed-loop experiments for a comparison of the performance of the LQR controller. For the closed-loop experiment, a square voltage, the same as the one used for obtaining the input-output data, was given as command voltage. Therefore, overshoot can be eliminated by optimally tuning $Q$ and $R$. The simulations guide the choices of $Q$ and $R$ for these experiments.

\subsubsection{Effect of Varying $Q$}

Figure 6 shows the effect of varying $Q$ when $R=0.01$. At $Q=700,000$ (Figure 6a) the DEA does not return to the initial position during the voltage OFF cycle. At $Q=70,000$ (Figure $6 \mathrm{~b}$ ) and $\mathrm{Q}=7000$ 
(Figure 6c), small overshoots can only be observed at the $\mathrm{ON}$ instances. For $\mathrm{Q}=700$ (Figure 6d) overshoots are observed in both the voltage ON and OFF phases. Theoretically, the DEA should have very high displacement if allowed to be driven by voltages higher than $1100 \mathrm{~V}$, as can be seen from the simulation results of Figure 4a where the value of $Q=700,000$ and $R=0.01$ resulted to a DEA displacement of $300 \mu \mathrm{m}$. For this LQR controller, the saturation limit was set at $1100 \mathrm{~V}$ to prevent the DEA from voltage breakdown. In our experiments, when the DEA is overdriven, it persists in one position of $55 \mu \mathrm{m}$ because of the saturation limit. From the experiments data, the graphs with no overshoots at the voltage OFF instances had $Q=70,000$ and 7000 when $R=0.01$. The open-loop response of Figure 6e shows overshoots and a similar response to Figure $6 \mathrm{~d}$ when $\mathrm{Q}=700$. This means that a low $Q$ value had little effect in minimizing the aggressiveness of the DEA's response. We select Figure $6 \mathrm{c}$ to be the optimal performance judging from its overshoot at the voltage $\mathrm{ON}$ instances being very small, with $Q=7000$ and $R=0.01$.

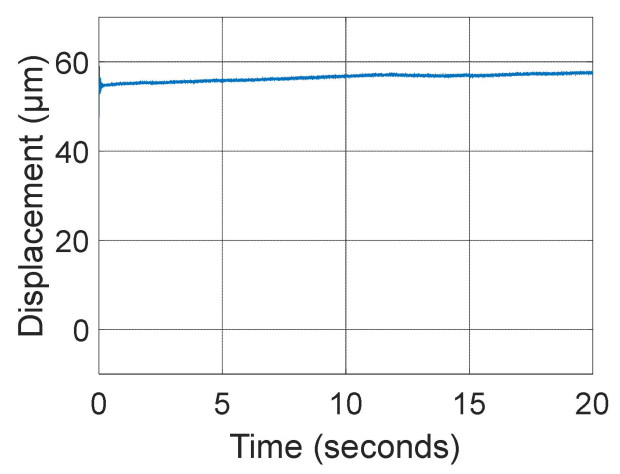

(a)

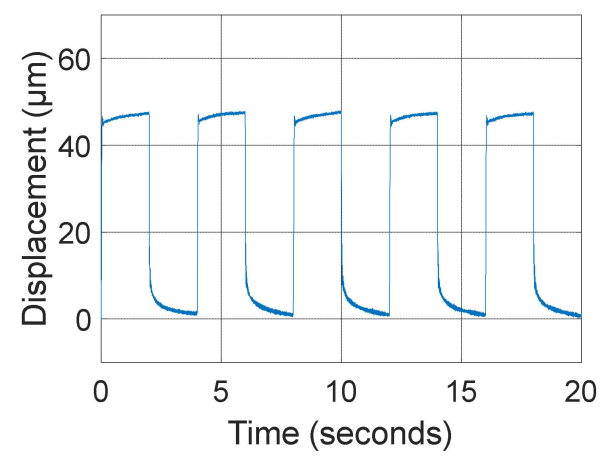

(c)

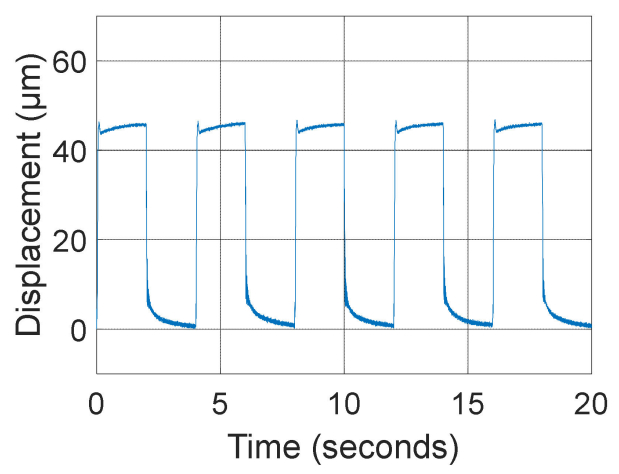

(b)

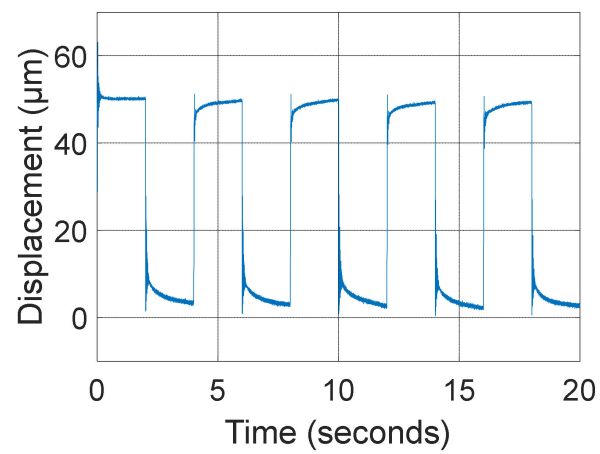

(d)

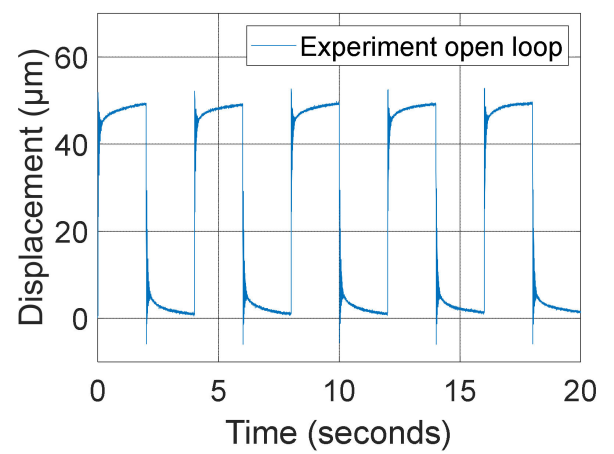

(e)

Figure 6. $\mathrm{LQR}$ closed-loop experimental response when varying $\mathrm{Q}$ while $\mathrm{R}=0.01$ : (a) $\mathrm{Q}=700,000$ (b) $\mathrm{Q}=70,000$ (c) $\mathrm{Q}=7,000$; (d) $\mathrm{Q}=700$, and (e) Open-loop experiment. 


\subsubsection{Effect of Varying $R$}

Figure 7 shows the experimental results for the effect of varying $R$ when $Q=70,000$. When $R=1$ (Figure 7a), overshoots are pronounced at both voltage ON and OFF instances. This performance of the DEA is similar to the open-loop performance of Figure 6e, implying that $R=1$ did not mitigate much the DEA's aggressive response. For $\mathrm{R}=0.1$ (Figure $7 \mathrm{~b}$ ) and 0.01 (Figure 7c), no overshoots can be seen at the voltage OFF instances. However, when $\mathrm{R}=0.001$ (Figure $7 \mathrm{~d}$ ), the DEA does not return to the initial position. The optimal performance is when $Q=70,000$ and $R=0.1$ judging from the peaks of Figure $7 b, c$ (Figure $7 b)$.

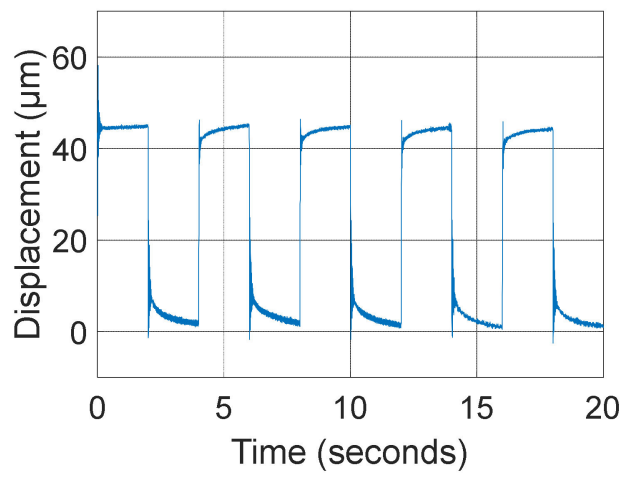

(a)

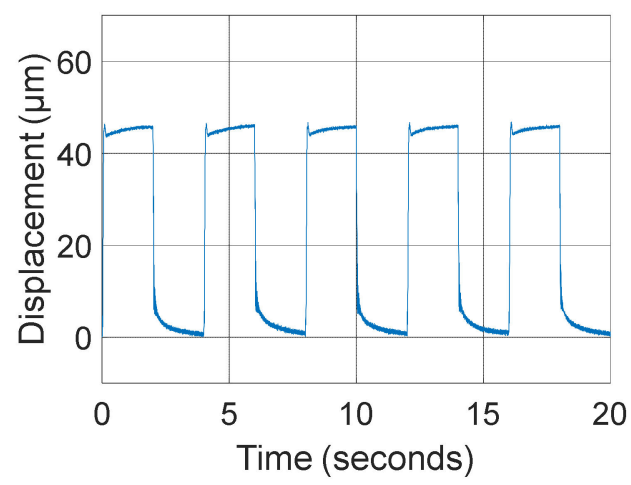

(c)

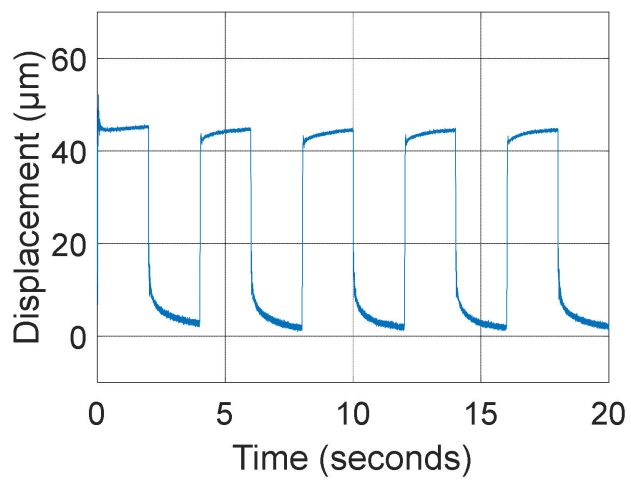

(b)

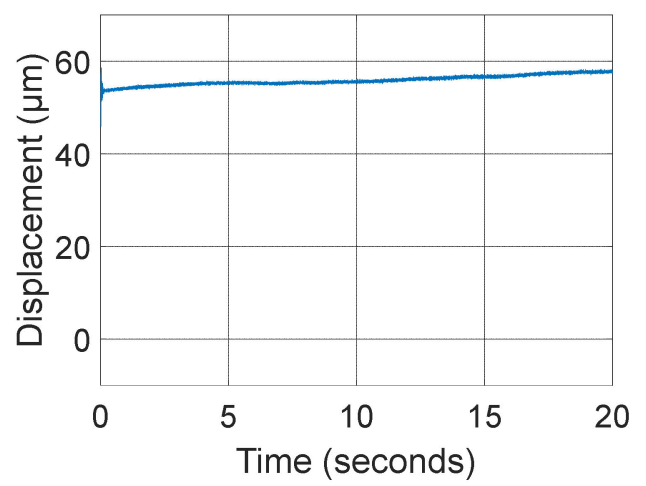

(d)

Figure 7. LQR closed-loop experimental response when varying $\mathrm{R}$ when $\mathrm{Q}=70,000$; (a) $\mathrm{R}=1$; (b) $\mathrm{R}=0.1 ;$ (c) $\mathrm{R}=0.01$; and, (d) $\mathrm{R}=0.001$.

\subsection{Comparison of Open-Loop and Closed-Loop Performance}

The open-loop and closed-loop performance for the simulations and the experiments were compared for shorter time scales when using the optimal parameters to investigate the effect of the LQR controller in the reduction of the overshoots of the DEA. The optimal weights for the LQR controller were $\mathrm{Q}=70,000, \mathrm{R}=0.1$, and $\mathrm{Q}=7000$ and $\mathrm{R}=0.01$.

A comparison of one of the voltage ON/OFF cycle (Figure 8a) for the identified model and the closed-loop simulations revealed that the LQR controller managed to remove the overshoots for both the voltage ON and OFF instances. A close look at the first $100 \mathrm{~ms}$ of Figure $8 \mathrm{a}$ shows that the identified model had a rise time of $10 \mathrm{~ms}$ and peak overshoot of 50\%, while the LQR controller led to a DEA response having a rise time of $20 \mathrm{~ms}$ (Figure $8 \mathrm{~b}$ ) with no overshoot.

Figure $8 \mathrm{c}$ shows the open-loop and closed-loop experiment time responses, respectively, for one voltage cycle. The LQR controller eliminated the overshoots at both the voltage ON and OFF instances Figure $8 \mathrm{~d}$ is a close-up of Figure $8 \mathrm{c}$ for the initial $100 \mathrm{~ms}$ duration during the voltage ON cycle. Here, the open-loop experiment showed a peak overshoot of $20 \%$ and a rise time of $10 \mathrm{~ms}$, while the closed-loop 
experiment reported a rise time of $20 \mathrm{~ms}$ with no overshoot. The LQR controller was beneficial in the removal of overshoots.

For both the closed-loop experiment and the closed-loop simulation (Figure 8e), they had no overshoots in their voltage ON and voltage OFF instances. Figure $8 \mathrm{f}$ is a close-up of Figure $8 \mathrm{e}$, where the $\mathrm{LQR}$ controller enabled the simulation and experiment to have a rise time of $20 \mathrm{~ms}$ with no overshoot. Therefore, the experiments validated the simulations.

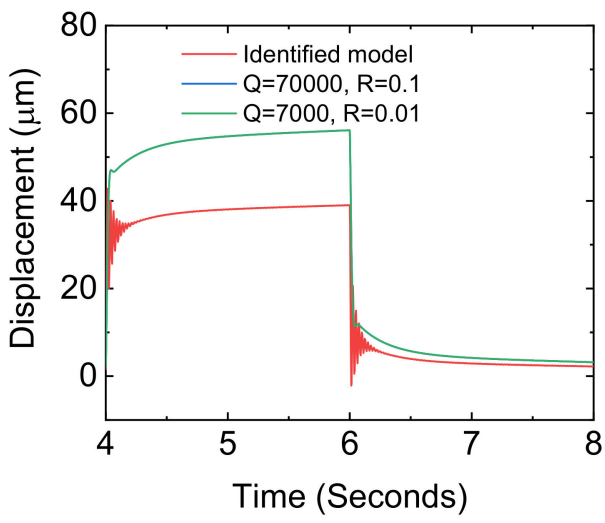

(a)

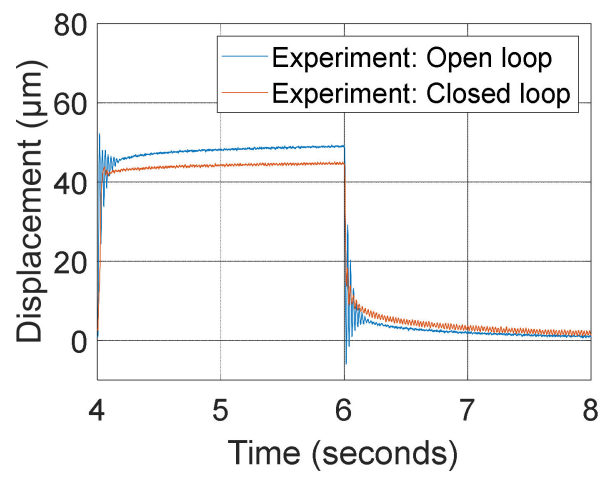

(c)

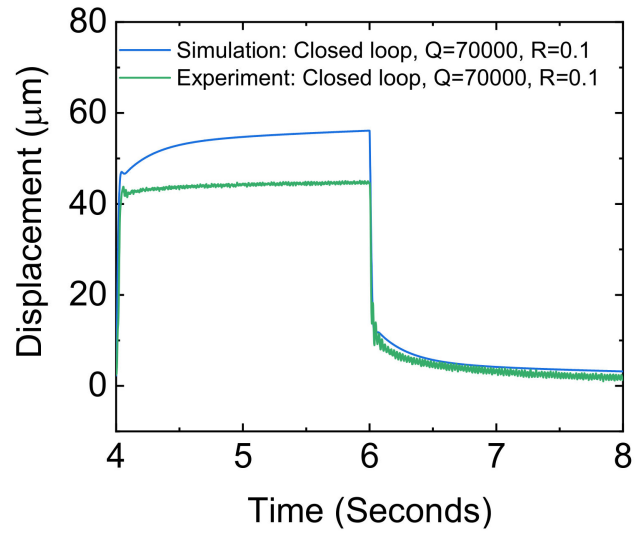

(e)

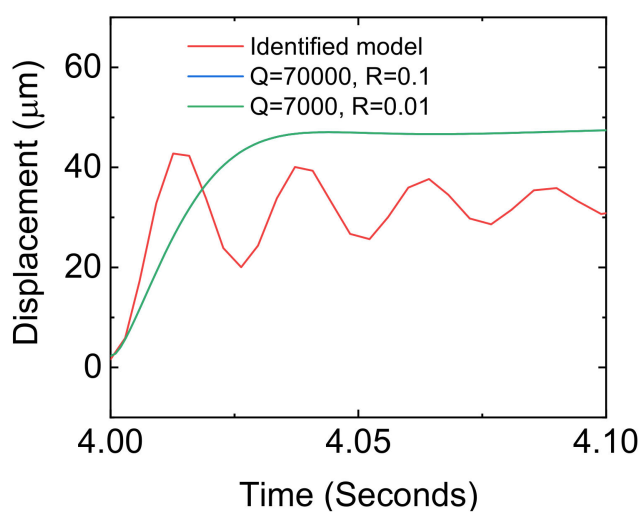

(b)

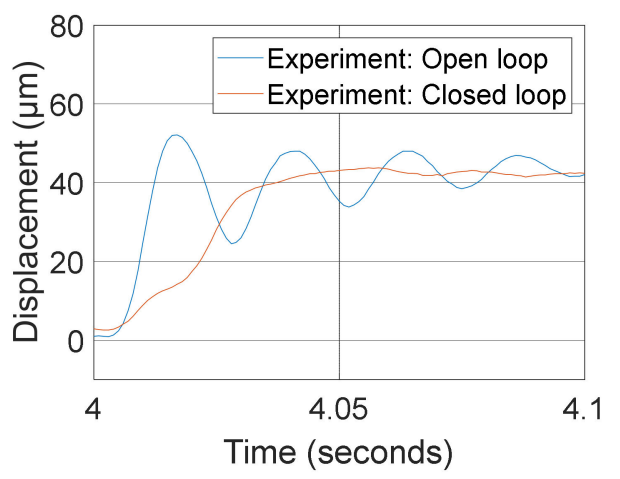

(d)

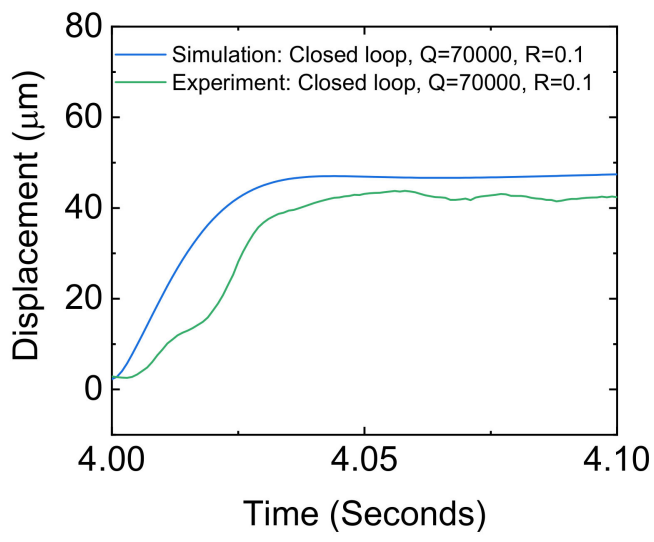

(f)

Figure 8. (a) Comparison of the identified DEA model and the closed-loop simulation for one voltage cycle; (b) A close-up of (a) For comparison of the identified DEA model and the closed-loop simulation for 100 ms duration; (c) Open-loop vs closed-loop experiment for one voltage cycle; (d) A close-up of (c) for 100 ms duration; (e) Comparison of closed-loop experiment and closed-loop simulation for one voltage cycle; and, (f) A close-up of (e) for 100 ms duration. 


\section{Conclusions}

In this paper, we have demonstrated the fabrication of a single layer cone DEA while using PDMS for the dielectric elastomer and an MWCNT/PDMS composite for the electrode. A stable transfer function of the cone DEA was obtained using system identification. A full state feedback LQR controller with a Luenberger state observer was implemented for the cone DEA. The parameters $Q$ and $R$ were tuned to obtain the optimal performance of the DEA. The optimal parameters, $Q=70,000, R=0.1$, and $Q=7000, R=0.01$ worked for both the simulation and the closed-loop experiment. The optimal response was when the DEA had zero overshoot with a rise time of $20 \mathrm{~ms}$, which was attained in both the simulations and closed-loop experiments when the final value was selected to be $100 \mathrm{~ms}$. This successful demonstration of the controllability of the DEA will further the realization of practical actuators for potential commercial applications, such as in the fabrication of the artificial muscles for use in high-frequency applications and in soft robotics.

Author Contributions: T.M. conceived this work. W.N., H.T., T.M. and T.N. performed the experiments. T.M. and W.N. performed the simulation. T.N., K.N., G.N. and M.S checked the validity of the work. T.M. and W.N. wrote the draft. M.S., T.N., H.T. and G.N. are the supervisors of T.M. All authors have read and agreed to the published version of the manuscript.

Funding: This project is supported by New Energy and Industrial Technology Development Organization (NEDO) in Japan, grant number 502000466, and Grant-in-Aid for Scientific Research Basic Research (B) (General) grant number $19 \mathrm{H} 02094$.

Conflicts of Interest: The authors declare no conflict of interest.

\section{References}

1. Gu, G.Y.; Zhu, J.; Zhu, L.M.; Zhu, X. A survey on dielectric elastomer actuators for soft robots. Bioinspir. Biomim. 2017, 12, 011003. [CrossRef] [PubMed]

2. Rus, D.; Tolley, M.T. Design, fabrication and control of soft robots. Nature 2015, 521, 467-475. [CrossRef] [PubMed]

3. Carpi, F.; Anderson, I.; Bauer, S.; Frediani, G.; Gallone, G.; Gei, M.; Graaf, C.; Jean-Mistral, C.; Kaal, W.; Kofod, G.; et al. Standards for dielectric elastomer transducers. Smart Mater. Struct. 2015, 24, 105025. [CrossRef]

4. Chen, B.; Kollosche, M.; Stewart, M.; Busfield, J.; Carpi, F. Electrical breakdown of dielectric elastomers: Influence of compression, electrode's curvature and environmental humidity. In Electroactive Polymer Actuators and Devices (EAPAD) 2016; International Society for Optics and Photonics: Washington, DC, USA, 2016; Volume 9798, pp. 1-10.

5. Carpi, F.; De Rossi, D.; Kornbluh, R.; Pelrine, R.E.; Sommer-Larsen, P. Dielectric Elastomers as Electromechanical Transducers: Fundamentals, Materials, Devices, Models and Applications of an Emerging Electroactive Polymer Technology; Elsevier: Amsterdam, The Netherlands, 2011; ISBN 0080557724.

6. Poulin, A.; Rosset, S.; Shea, H.R. Printing low-voltage dielectric elastomer actuators. Appl. Phys. Lett. 2015, 107, 244104. [CrossRef]

7. Rosset, S.; O’Brien, B.M.; Gisby, T.; Xu, D.; Shea, H.R.; Anderson, I.A. Self-sensing dielectric elastomer actuators in closed-loop operation. Smart Mater. Struct. 2013, 22, 104018. [CrossRef]

8. Brochu, P.; Pei, Q. Advances in dielectric elastomers for actuators and artificial muscles. Macromol. Rapid Commun. 2010, 31, 10-36. [CrossRef]

9. Rosset, S.; Shea, H.R. Small, fast, and tough: Shrinking down integrated elastomer transducers. Appl. Phys. Rev. 2016, 3, 31105. [CrossRef]

10. O'Halloran, A.; O'malley, F.; McHugh, P. A review on dielectric elastomer actuators, technology, applications, and challenges. J. Appl. Phys. 2008, 104, 9. [CrossRef]

11. Hoffstadt, T.; Maas, J. Self-sensing Algorithms for Dielectric Elastomer Multilayer Stack-Transducers. IFAC Pap. 2016, 49, 373-379. [CrossRef]

12. Kovacs, G.; Düring, L.; Michel, S.; Terrasi, G. Stacked dielectric elastomer actuator for tensile force transmission. Sens. Actuators A Phys. 2009, 155, 299-307. [CrossRef] 
13. Hau, S.; Rizzello, G.; Seelecke, S. A novel dielectric elastomer membrane actuator concept for high-force applications. Extrem. Mech. Lett. 2018, 23, 24-28. [CrossRef]

14. Hau, S.; Rizzello, G.; Hodgins, M.; York, A.; Seelecke, S. Design and control of a high-speed positioning system based on dielectric elastomer membrane actuators. IEEE/ASME Trans. Mechatron. 2017, 22, 1259-1267. [CrossRef]

15. Rizzello, G.; Naso, D.; Turchiano, B.; Seelecke, S. Robust Position Control of Dielectric Elastomer Actuators Based on LMI Optimization. IEEE Trans. Control. Syst. Technol. 2016, 24, 1909-1921. [CrossRef]

16. Hodgins, M.; Rizzello, G.; York, A.; Naso, D.; Seelecke, S. A smart experimental technique for the optimization of dielectric elastomer actuator (DEA) systems. Smart Mater. Struct. 2015, 24, 094002. [CrossRef]

17. Rizzello, G.; Fugaro, F.; Naso, D.; Seelecke, S. Simultaneous Self-Sensing of Displacement and Force for Soft Dielectric Elastomer Actuators. IEEE Robot. Autom. Lett. 2018, 3, 1230-1236. [CrossRef]

18. Fasolt, B.; Hodgins, M.; Rizzello, G.; Seelecke, S. Effect of screen printing parameters on sensor and actuator performance of dielectric elastomer (DE) membranes. Sens. Actuators A Phys. 2017, 265, 10-19. [CrossRef]

19. Rizzello, G.; Naso, D.; Seelecke, S. A Nonlinear Electro-Mechanical Model for an Annular Dielectric Elastomer Actuator with a Biasing Mass. VDI Tag. Mechatronik 2013, 117-122.

20. Hodgins, M.; Rizzello, G.; Naso, D.; York, A.; Seelecke, S. An electro-mechanically coupled model for the dynamic behavior of a dielectric electro-active polymer actuator. Smart Mater. Struct. 2014, 23, 104006. [CrossRef]

21. Rizzello, G.; Naso, D.; York, A.; Seelecke, S. Model. Based PID Control of a Dielectric Electro-Active Polymer Positioning System; IFAC: Geneva, Switzerland, 2014; Volume 19, ISBN 9783902823625.

22. Fadel, M.; Carriere, S.; Caux, S. Optimal LQI synthesis for speed control of synchronous actuator under load inertia variations. IFAC Proc. Vol. 2008, 17, 5831-5836.

23. Mallavarapu, K.; Leo, D.J. Feedback control of resonant modes in bending response of ionic polymer actuators. Am. Soc. Mech. Eng. 2001, 64, 283-292.

24. Zou, J.; Gu, G.Y.; Zhu, L.M. Open-loop control of creep and vibration in dielectric elastomer actuators with phenomenological models. IEEE/ASME Trans. Mechatron. 2017, 22, 51-58. [CrossRef]

25. Zou, J.; Gu, G. High-precision tracking control of a soft dielectric elastomer actuator with inverse viscoelastic hysteresis compensation. IEEE/ASME Trans. Mechatron. 2019, 24, 36-44. [CrossRef]

26. Zou, J.; Gu, G. Modeling the viscoelastic hysteresis of dielectric elastomer actuators with a modified rate-dependent Prandtl-Ishlinskii model. Polymers 2018, 10, 525. [CrossRef] [PubMed]

27. Gu, G.Y.; Gupta, U.; Zhu, J.; Zhu, L.M.; Zhu, X. Modeling of Viscoelastic Electromechanical Behavior in a Soft Dielectric Elastomer Actuator. IEEE Trans. Robot. 2017, 33, 1263-1271. [CrossRef]

28. Branz, F.; Francesconi, A. Modelling and control of double-cone dielectric elastomer actuator. Smart Mater. Struct. 2016, 25, 95040. [CrossRef]

29. Meng, L.; Bao, W.; Li, F.; Li, H. Hysteresis compensation control of a dielectric elastomer vibration isolator. J. Low Freq. Noise Vib. Act. Control. 2019. [CrossRef]

30. Jones, R.W.; Sarban, R. Model validation and feedback controller design for a dielectric elastomer actuator. J. Intell. Mater. Syst. Struct. 2016, 27, 2078-2090. [CrossRef]

31. Khosla, A.; Gray, B.L. Preparation, characterization and micromolding of multi-walled carbon nanotube polydimethylsiloxane conducting nanocomposite polymer. Mater. Lett. 2009, 63, 1203-1206. [CrossRef]

32. Mulembo, T.; Nagai, G.; Tamagawa, H.; Nitta, T.; Sasaki, M. Conductive and flexible multi-walled carbon nanotube/polydimethylsiloxane composites made with naphthalene/toluene mixture. J. Appl. Polym. Sci. 2019, 136, 48167. [CrossRef]

33. Bauman, J.T.; Bauman, J.T. Fatigue, Stress, and Strain of Rubber Components; Carl Hanser Verlag GmbH Co KG: Munich, Germany, 2012; ISBN 3446433406.

(C) 2020 by the authors. Licensee MDPI, Basel, Switzerland. This article is an open access article distributed under the terms and conditions of the Creative Commons Attribution (CC BY) license (http://creativecommons.org/licenses/by/4.0/). 